\title{
Development and evaluation of a bladder Cancer specific survivorship care plan by patients and clinical care providers: a multi- methods approach
}

Cheryl T. Lee ${ }^{1 \dagger}$, Nihal E. Mohamed ${ }^{2 *+}$, Sailaja Pisipati ${ }^{3}$, Qainat N. Shah ${ }^{2}$, Piyush K. Agarwal ${ }^{4}$, Tracy M. Downs ${ }^{5}$, Michael Droller ${ }^{2}$, Scott M. Gilbert ${ }^{6}$, Heather H. Goltz ${ }^{7,8}$, Simon J. Hall ${ }^{9}$, Mohamed Hendawi ${ }^{1}$, Jean Hoffman-Censits ${ }^{10}$, Michael O'Donnell ${ }^{11}$, Matthew Kaag ${ }^{12}$, Lawrence I. Karsh ${ }^{13}$, Wassim Kassouf ${ }^{14}$, Diane Z. Quale ${ }^{15}$, Arthur Sagalowsky ${ }^{16}$, Gary D. Steinberg ${ }^{17}$ and David M. Latini ${ }^{18}$

\begin{abstract}
Background, context and purpose: In spite of the mixed evidence for their impact, survivorship Care Plans (SCPS) are recommended to enhance quality of care for cancer survivors. Data on the feasibility of SCPs in bladder cancer (BC) is sparse. Using a mixed-methods approach, this study describes the iterative development, acceptability and feasibility of BC specific SCP (BC-SCP) in clinical settings.
\end{abstract}

Methods: In Phase I, we developed the BC-SCP. In Phase II, we conducted four focus groups with 19 patients and 15 providers to examine its acceptability and usability challenges. Data analyses using the Atlas.ti program, informed refinement of the BC-SCP. In Phase III, we conducted feasibility testing of the refined BC-SCP with 18 providers from 12 health-centers. An encounter survey was completed after each assessment to examine the feasibility of the BC-SCP. Chi-square and Fisher Exact tests were used for comparative analyses.

Results: During phase I, we observed high patient and provider acceptability of the BC-SCP and substantial engagement in improving its content, design, and structure. In Phase II, providers completed 59 BC-SCPs. Mean time for BC-SCP completion was 12.3 min. Providers reported that BC-SCP content was clear, did not hamper clinic flow and was readily completed with easy-to-access information. Comparative analyses to examine differences in SCP completion time by patient clinico-demographic characteristics and provider type revealed no significant differences.

Conclusions: Our BC-SCP has clinical relevance, and can be used in an active practice setting. However, considerable progress will be necessary to achieve implementation of and sharing the BC-SCP with patients and care providers, particularly within the electronic medical record. In summary, BC-SCPs are essential to improve the follow up care of BC survivors. Clinical resources are required to ensure appropriate implementation of BC-SCPs.

(Continued on next page)

\footnotetext{
* Correspondence: nihal.mohamed@mountsinai.org

Cheryl T. Lee and Nihal E. Mohamed are 1st Co-authorship

${ }^{2}$ Department of Urology and Oncological Sciences, Icahn School of Medicine

at Mount Sinai, 1 Gustave L Levy Place, New York, NY 10029, USA

Full list of author information is available at the end of the article
}

(C) The Author(s). 2020 Open Access This article is licensed under a Creative Commons Attribution 4.0 International License, which permits use, sharing, adaptation, distribution and reproduction in any medium or format, as long as you give appropriate credit to the original author(s) and the source, provide a link to the Creative Commons licence, and indicate if changes were made. The images or other third party material in this article are included in the article's Creative Commons licence, unless indicated otherwise in a credit line to the material. If material is not included in the article's Creative Commons licence and your intended use is not permitted by statutory regulation or exceeds the permitted use, you will need to obtain permission directly from the copyright holder. To view a copy of this licence, visit http://creativecommons.org/licenses/by/4.0/ The Creative Commons Public Domain Dedication waiver (http://creativecommons.org/publicdomain/zero/1.0/) applies to the data made available in this article, unless otherwise stated in a credit line to the data. 
(Continued from previous page)

Trial registration: Study HUM00056082.

Keywords: Survivorship care plan, Bladder Cancer specific survivorship care plan, Focus groups, Care providers, Muscle invasive bladder Cancer, Non-muscle invasive bladder Cancer

\section{Background}

Bladder cancer $(\mathrm{BC})$ is the second most common genitourinary cancer in the United States accounting for $4.5 \%$ of all new cancer cases worldwide [1]. The diagnosis and management of $\mathrm{BC}$ causes significant psychological stress due to invasive treatments, short- and long-term side effects, life-long self-care requirements (e.g., utility of stomal appliances and catheterization), and extensive cancer surveillance [2]. We and others have shown that significant unmet informational needs and supportive care needs persist throughout the BC trajectory including survivorship [2-4]. Although the need for information about BC, treatment options, short-term sideeffects, and self-care skills is readily apparent after cancer diagnosis and treatment, the need for management of long-term side-effects (e.g., urinary incontinence, sexual dysfunction, and psychological adjustment to altered body-image) is often unrecognized $[2,4,5]$. In spite of the importance, variability, and persistence of information and supportive care needs in $\mathrm{BC}$ patients, resources to meet these needs are very limited (e.g., support groups, survivorship programming, and patient navigation/information) $[2,4,5]$.

In view of the increasing proportion of cancer survivors, centralization of advanced services in tertiary units, and patient desire to maximize local care for cancer surveillance, a shared care approach between urologists, oncologists, regional primary care physicians (PCPs) and advanced practice providers (APPs) might provide highquality of survivorship care. Evidence supports surveillance models anchored in community-based survivorship care, which are non-inferior to oncologist-based care [6, 7]. Consequently, the American Society of Clinical Oncology (ASCO) recommends a shared care model between oncologists and PCPs for breast cancer survivorship; the level of shared care would be dependent upon the preferences of providers and survivors as well as available resources $[8,9]$. Challenges to the communitybased survivorship model include a lack of specialized experience in managing the complex needs of survivors $[10,11]$, scarcity of time to counsel patients about survivorship issues, complications of cancer treatments, psychosocial support, symptom management, and selfcare $[4,5,11,12]$.

The Institute of Medicine (IOM), the National Comprehensive Cancer Network (NCCN), and American College of Surgeons Commission on Cancer (CoC) efforts to improve survivorship have led to major recommendations for enhancing cancer survivor's care quality and follow-up care [5, 7]. One of these recommendations is the provision of Survivorship Care Plans (SCPs) to patients and their PCPs [13]. SCP is a personalized document summarizing patient's diagnosis, treatment, surveillance and pertinent resources $[13,14]$. The key elements of SCPs include prevention and detection of recurrent cancers, regular surveillance, interventions for longterm effects of the cancer and treatments, and coordination between PCP and specialists to ensure that survivor needs are met $[13,15,16]$. The IOM survivorship model emphasizes the value of a team approach of qualified specialists who collaborate to address patients' unmet clinical and psychosocial supportive care needs during survivorship. This model recognizes existing gaps in clinical care as well as lack of multidisciplinary care approach contributing to patient existing needs and challenges in cancer survivorship.

Several SCPs have been formally developed for patients with childhood [17-19], breast [7, 20-23], gynecological [24] and colorectal cancers [25, 26], to help improve documentation and coordination of cancer treatment and survivorship care. A systematic review of these studies [27] has shown that the use of SCPs has resulted in high levels of cancer survivor satisfaction, high levels of survivor perception that SCPs enhanced communication between providers, and variable levels of distress [27, 28]. Increasing evidence points to the benefits and efficacy of survivorship care plans in reducing fatigue and distress, and improving long-term physical health and emotional well-being, physician-patient communication, patient experiences, and knowledge of recommended follow-up care [29, 30]. SCPs therefore provide an opportunity to engage survivors in their health care, while also capturing meaningful treatmentrelated outcomes to use as basis for making informed decisions [31]. However, research findings were not consistent in reporting these benefits as some studies failed to report these positive outcomes of the utility of SCPs in patients $[21,23,24]$. Reasons for the inconsistent research findings may be related to the use of different research methods, patient cohorts, or evaluation measures of patient' outcomes.

$\mathrm{BC}$ patients represent a population likely to benefit from a disease-specific SCP (BC-SCP). In addition to the variability, persistence, and significant unmet informational and supportive care needs reported by this population across the disease trajectory, most of these patients are 
often treated regionally by specialists, creating an important need for communication with local physicians and other providers. We developed a disease-specific SCP to meet this need. While the use of generic SCPs among $\mathrm{BC}$ patients is largely unexplored, we hypothesize that a $\mathrm{BC}$-SCP could improve patientprovider communication and bring a level of comprehensiveness and continuity to surveillance visits without adding burden to already busy provider clinics. We also believe that a BC-SCP will bring attention to the many unique unmet needs experienced by this population $[4,32,33]$. While we believe that SCPs play an essential role in improving communication and coordination between providers thus facilitating survivorship care among BC patients, availability of resources including clinic manpower, time, training and reimbursement, could be the potential challenges to foresee. In this study, we examined the acceptability and feasibility (i.e., the uptake and completion of the BC-SCP by clinical providers) of a BC-SCP we developed specifically for both nonmuscle invasive bladder cancer (NMIBC) and muscle invasive bladder cancer (MIBC) patients.

\section{Methods}

This study was conducted between October 2011 and October 2012 and was approved by the Institutional Review Board (IRB) of the University of Michigan (the lead institution) and the participating institutions. Prior to the patient and provider focus groups (FG; Phase I) and provider usability study (Phase II), informed consent was obtained from the study participants. All study participants (Phase I and II) were consented before participation, were given a detailed description about the purpose of this project and ensured anonymity and confidentiality of their responses. FG participants received an honorarium of $\$ 100$ for their time and transportation costs. The different phases of our work including the design, development, qualitative review leading to refinement of the content and evolution of our BC-SCP as well as the feasibility of it's application into clinical practice is described below (Fig. 1).

\section{Phase I: the development of the BC-SCP}

The BC-SCP (Additional file 1) was developed by two members of the research team - a urologist (CTL) and clinical psychologist (DML). In collaboration with The

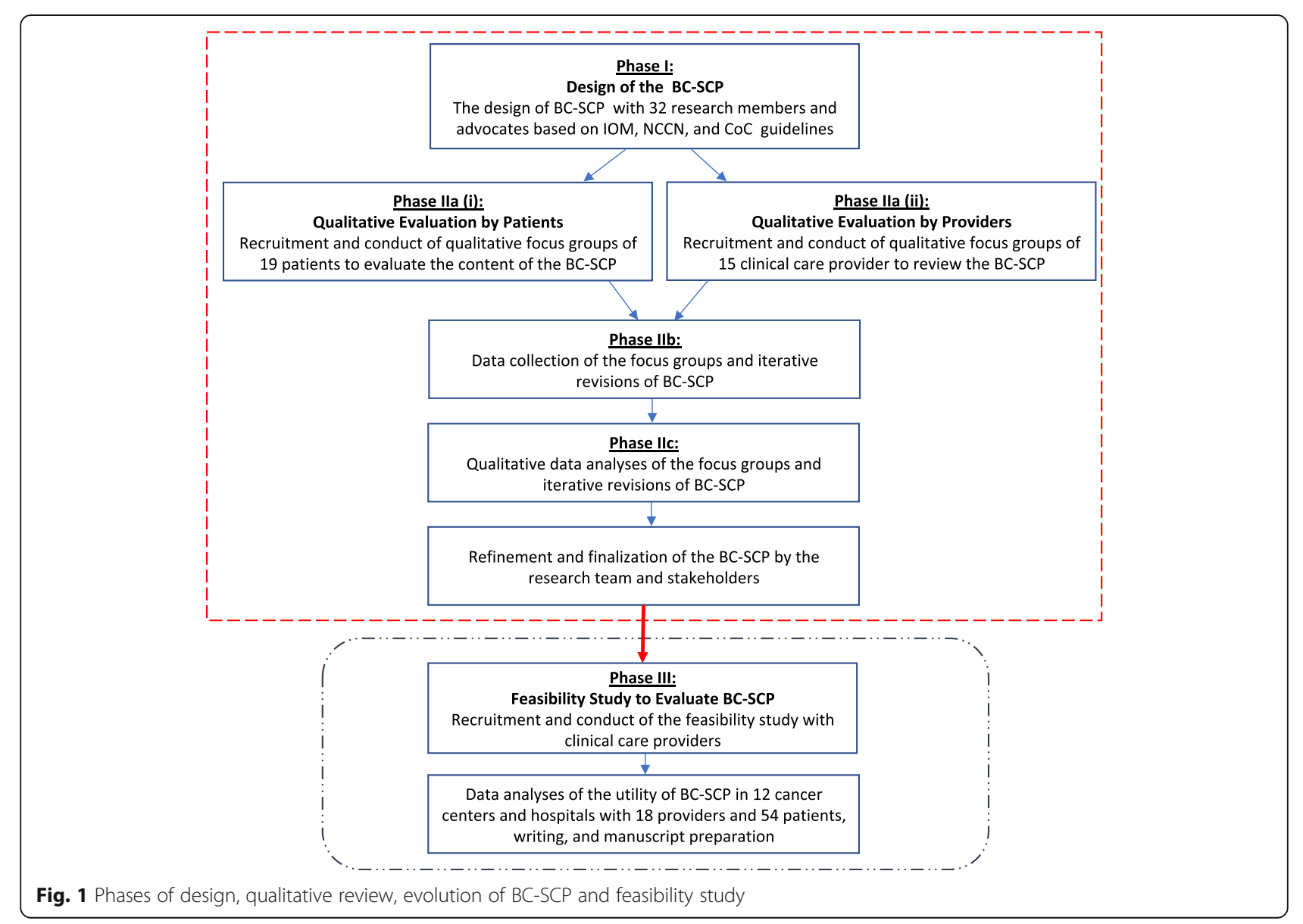


Survivorship Working Group of the Bladder Cancer Advocacy Network (BCAN-SWG) co-chaired by the same two members at the time of this study, the BCSCP was iteratively reviewed and refined by all BCAN-SWG members including urologic oncologists, general urologists, medical oncologists, radiation oncologists, PCPs, physician extenders, nurse specialists, social scientists, BC survivors, and patient advocates $(N=32)$. The developers' intent is to use the BC-SCP to summarize the treatment process of the patient and the aftercare that is needed for recovery, longterm surveillance, early detection of cancer recurrence, and overall health promotion [34].

Guidelines for SCPs recommended by the IOM, $\mathrm{NCCN}$, and CoC informed the content, structure, and design of the BC-SCP $[5,7]$. Following these guidelines, our BC-SCP (Additional file 1) incorporates sections for general and background information (Sections I and II), prior and planned treatment (Section III), and cancer surveillance (Section IV). An appendix to the care plan (Additional file 2) provides information regarding cancer prevention and health maintenance (Section A-I), "redflag' symptoms that should be reported (Section A-II), late effects of cancer and its treatment (Section A-III), and resources for providers and patients (Sections A-IV through A-VI). Lastly, a glossary is included in Section A-VII. Although healthcare providers are expected to complete and continue updating the BC-SCP, it is designed to also provide critical resource information to enhance patient-provider communication and to address common needs of BC patients (e.g., information about -ostomy nurses and support groups in the community). We designed BC-SCP for both low and high health literacy patients (Additional file 1) and added a Glossary to explain medical and clinical terms (Additional file 2).

\section{Phase II: qualitative evaluation of the BC-SCP by patients and clinical providers \\ Phase lla: study participants}

Following the revision of the BC-SCP based on BCAN-SWG reviews, we conducted two FGs with 19 $\mathrm{BC}$ patients clustered by gender (i.e., 11 male vs. 8 female groups) and two FGs with 7 physicians (e.g., urologists and oncologists) and 6 non-physician providers (e.g., physician assistants-PAs, nurse practitioners-NPs, social worker). The main goal of the FGs was to explore the acceptability of the content, design, structure, readability, and feasibility of the revised BC-SCP from both patient and provider perspectives. Time duration for each group ranged between 60 and $120 \mathrm{~min}$. The providers (i.e., physician and non-physician) FGs were led by CTL and patient FGs were led by DML. Each FG met separately with the two facilitators (CTL and DML).

\section{Phase IIb: data collection}

Provider FG discussions were held over the phone and provided valuable input into 1) challenges faced by providers, 2) content of the BC-SCP, 3) the consolidation of health information from various provider sources, 4) treatment related complications, 5) psychosocial impact, 6) optimization of the surveillance plan, and 7) followup care. Additionally, they were asked about the quality of information regarding patient, care-giver, and provider resources. The facilitators then met with the male and female patient groups in person in a designated conference room space. Topics of interest that arose during the patient FGs included 1) patient awareness of disease, treatment and surveillance characteristics, 2) treatment complications, 3) unmet needs that emerge at diagnosis, after treatment, and during survivorship, and 4) a clear understanding of the BC-SCP content.

\section{Phase Ilc: data analysis}

Following guidelines [35, 36], all FGs have been taperecorded and transcribed verbatim. Two members of the research team (CTL and DML) met immediately after each FG to discuss critical points and notable quotes, and to identify topics that need more probing and clarifications in subsequent FGs. Tapes have been transcribed and interpreted through an iterative process of thematic content analysis using ATLAS.ti [37] by a third member of the research team (NEM) $[35,36]$. Negotiated discussions (CTL, DML, HHG, and NEM) resolved discrepancies in emerging codes; findings revealed important characteristics and limitations of the BC-SCP. Results have been incorporated in further revisions of the BC-SCP's content, structure, and readability.

\section{Phase III: feasibility study and survey evaluation of the BC-SCP with clinical providers \\ Phase Illa: study participants}

Urologic or medical oncologists, or APPs (including NP, PA) recruited new MIBC or NMIBC patients to be interviewed during standard clinic evaluations. Randomization method was not employed while selecting patients as the purpose of the study was to examine the feasibility of the SCP in clinical settings from the provider's perspective using a convenient sample of patients. BC-SCP was completed on each patient. Data detailing the completion of the $\mathrm{BC}-\mathrm{SCP}$ and the related encounter was captured. Each center was asked to complete a minimum of four SCPs, including two with MIBC and at least two with NMIBC. During clinical consultations, the BC-SCP was discussed with the patient; but SCPs were not handed over to patients, and patients were not asked to complete these SCPs, as the major goal of this study was to determine the feasibility of SCPs by providers in day to day medical practice in 
office based settings. Generic appendices containing patient resources and health information were provided to patients. Patient identifiers were not included in the BCSCP.

\section{Phase IIIb: data collection}

An encounter data questionnaire developed by the research team for this study (Additional file 3) comprising of an 8-item survey using a seven-point Likert response scale (1-'not at all' to 7-'very much') was provided to participants to examine their evaluation of the BC-SCP and its feasibility. Single items assessed clarity of the $\mathrm{BC}-\mathrm{SCP}$, ease of use, ability to complete the $\mathrm{BC}-\mathrm{SCP}$ during a clinical encounter, availability of resources to complete the BC-SCP, patient participation in completing the $\mathrm{BC}-\mathrm{SCP}$, use of $\mathrm{BC}$-SCP to enhance patient-provider communication, and the degree of patient interest in receiving the patient resources and health information section of the BC-SCP. The survey-items also include questions assessing site characteristics (e.g., academic, private, Veteran Affair, other clinical settings), availability of EMR, provider characteristics (e.g., provider name, specialty, type, years in practice, and gender), availability of clinic support staff, willingness to complete the BC-SCP without reimbursement, number of rooms allocated to the clinic (e.g., general, consultation, and procedure rooms), and suggestions for improving the content of the BC-SCP.

\section{Phase IIIc: data analysis}

Both descriptive and comparative analyses were conducted to explore the feasibility and evaluation of the BC-SCP by providers (e.g., clarity of information). Statistical analyses described 1) site and provider characteristics, 2) completion time, and 3) provider evaluation of their actual use of the BC-SCP. Missing data was deleted automatically from the analyses. Imputation or missing value replacements were not used due to small sample size, and single item questions used to assess study outcomes. Comparative analyses were conducted on BC-SCP completion time stratified by patient clinico-pathologic parameters and provider specialty (urologist vs. other). Time to complete the $\mathrm{BC}-\mathrm{SCP}$ was categorized into 1$) \leq 10 \mathrm{~min}$, versus 2 ) > $10 \mathrm{~min}$. Comparative analyses were conducted by means of the Chi-square test and confirmed by Fisher Exact test, a more conservative proportioncomparison test [38]. Significant differences were confirmed only with a two-tailed Fisher probability $\left(P_{\text {Fisher }}<.05\right)$ [38]. Percentages were calculated to describe the frequencies within time groups $(\leq 10 \mathrm{~min}$ and $>10 \mathrm{~min}$ ). Quantitative descriptive analyses of data collected was carried out using SPSS analytical software.

\section{Study results \\ Phase Ila (i): qualitative evaluation of the BC-SCP by patients}

Challenges in $\mathrm{BC}$ clinical care and treatment outcomes reported by the patients included lack of full information about diagnosis, treatment, and outcomes; need for both written and visual educational tools about basic stoma care; change in urinary, sexual, and bowel function; nutrition; expectations regarding cystectomy and urinary diversion; and clinical support with psychological issues including altered body image, depression and anxiety. All patients reported that having BC-SCP would be helpful in updating the PCPs on recent results, treatments and follow-up plans; regular health promotion; and patient specific needs. Patients also felt that including detailed information regarding all the support resources available would be highly beneficial. Results of the qualitative assessments of both patients and providers informed further improvement in the content, structure, and delivery method of the BC-SCP (i.e., paper versions and electronic versions were made available for the usability testing of the $\mathrm{BC}-\mathrm{SCP}$ ).

\section{Phase Ila (ii): qualitative evaluation of the BC-SCP by clinical providers}

Challenges in BC clinical care reported by the providers included patient education; treatment decision making, specifically in the context of neoadjuvant chemotherapy and urinary diversion; clinical care of patients failing intravesical therapies for NMIBC in the geriatric population; smoking cessation and psychological distress; and patient adherence to cancer surveillance. Although all providers reported high acceptability of the content, structure, and potential use of the $\mathrm{BC}-\mathrm{SCP}$, challenges and concerns about using the $\mathrm{BC}-\mathrm{SCP}$ in the clinical setting was reported. These included the volume and breadth of information contained in the BC-SCP that might not be relevant to individual patients (i.e., depending on the specific cancer stage, treatment, and complications). This coupled with issues of scanning the $\mathrm{BC}$ SCP into the media section in EPIC, manual data collection, and the inability to edit scanned information for future updates or changes in care, raised concerns in the feasibility of the paper version of the BC-SCP in busy clinics. All providers felt that an electronic version incorporated into the EMR would better facilitate care. Suggestions for improvement included the addition of contact details of stoma care nurses, pharmacists, physical therapists, and nutritionists as part of the care team involved in patient care. Reimbursement to account for 
provider time to complete the $\mathrm{BC}-\mathrm{SCP}$ was another concern.

\section{Phase III: the feasibility of the BC-SCP}

Twelve high-volume (i.e., $>50$ cases/year) academic health-centers in the United States (US) and Canada, and one private practice group enrolled patients in this prospective clinical pilot. Of the 12 cancer centers and hospitals that participated in this study (Table 1), 90.9\% had academic affiliations, and $72.7 \%$ had access to EMR. Of those with no active EMR, $66.7 \%$ had an EMR pending within 1 year. Of the 18 care providers who participated in this study, $81.2 \%$ were male, $36.4 \%$ reported having more than 20 years of experience in clinical practice (Table 2), $77.8 \%$ were urologists, $5.6 \%$ were medical oncologists and $16.6 \%$ were other care providers (i.e., NP, PA, medical assistants, social workers, residents, fellows, or student volunteers) (Table 3).

Fifty-nine $\mathrm{BC}$ patients were evaluated with the $\mathrm{BC}$ SCP. Follow-up care plans were complete and valid for data-analysis in 54 (i.e., $92 \%$ completion rate) patients of whom $74.5 \%$ were male, $94.2 \%$ were Caucasians, $37.1 \%$ had MIBC, and $45.1 \%$ had Medicare as their primary medical insurance. Majority of the BC-SCPs were completed by urologists $(75.9 \%)$ and $98 \%$ of BC-SCPs were completed before or after consultation with patients; 90\% were completed within the confines of the clinic. The mean time to complete the SCP was $12.3 \mathrm{~min}(\mathrm{SD}=$ 6; range: $2-25 \mathrm{~min}$ ).

Frequencies of variables such as demographics of the patient, disease stage, insurance type, type of provider and their experience stratified within time groups $(\leq 10$ $\min$ and $>10 \mathrm{~min}$ ) are shown in Table 4 . Comparative analyses to examine differences in SCP completion time by clinical and demographic characteristics and provider type revealed no significant differences.
None of the care providers reported that completing the BC-SCPs resulted in higher billing codes. Provider experience with the BC-SCP is summarized in Table 5 . Although the BC-SCP was clear and information to complete it was readily available, there was evidence that it may have had a negative impact on clinic flow. There was also some uncertainty expressed regarding the availability of clinic resources to complete $\mathrm{BC}$-SCPs in all new BC patients. Since nearly all BC-SCPs were not completed in the presence of the patient, the patient was not active in its completion and the BC-SCP did not enhance dialogue with the provider.

\section{Discussion}

The major goals of this study are to examine the acceptability and feasibility of a BC specific SCP that we developed for patients to improve care and adherence to cancer surveillance. The current study qualitative and quantitative results demonstrated the high acceptability of the BC-SP by both patients and providers and completion rates of the $\mathrm{BC}-\mathrm{SCP}$ in clinical settings by providers. Qualitative outcomes also confirmed some of the challenges experienced in $\mathrm{BC}$ care and in attempting to integrate BC-SCPs into clinical practice. These reported challenges by patients and providers confirmed our prior research findings on unmet needs of $\mathrm{BC}$ patients $[2,4]$ and their suggestions for BC-SCP improvement were integrated in iterative revisions of the content and design of the BC-SCP and its appendices (e.g., online BC support groups; ostomy nurses in the community).

Phase III feasibility survey data revealed that although providers had access to a clear and concise BC-SCP that could be completed in the clinic, its use did not enhance patient engagement or the patient-physician interaction because of time constraints. This is likely to reduce expected patient benefits from BC-SCP discussions. Providers had a mean number of three clinic rooms and

Table 1 Participating Sites

\begin{tabular}{lll}
\hline Site & Provider Type & Number of Patients \\
\hline Icahn School of Medicine at Mount Sinai, NY, USA & Urologist & 6 \\
University of Michigan, MI, USA & Urologist & 5 \\
Sidney Kimmel Cancer Center at Jefferson, PA, USA & Medical Oncologist & 5 \\
University of Wisconsin School of Medicine and Public Health, WI, USA & Urologist & 5 \\
Penn State Hershey Medical Center, PA, USA & Urologist & 5 \\
McGill University Health Center, Quebec, CANADA & Urologist & 5 \\
University of lowa, IA, USA & Urologist & 5 \\
University of Texas Southwestern Medical Center, TX, USA & Urologist & 5 \\
University of Chicago, IL, USA & Advanced Practice Providers & 5 \\
Urology Center of Colorado, CO, USA & Urologists & 5 \\
University of Florida, FL, USA & Urologist & 2 \\
National Cancer Institute, MD, USA & Urologist & 1 \\
\hline
\end{tabular}


Table 2 Site Characteristics

\begin{tabular}{|c|c|c|}
\hline & $\mathrm{n}$ & $\%$ \\
\hline No of Sites & 12 & - \\
\hline Site Leader & 12 & - \\
\hline \multicolumn{3}{|l|}{ Provider Gender } \\
\hline Male & 9 & 81 \\
\hline Female & 2 & 18 \\
\hline \multicolumn{3}{|l|}{ Years in Practice } \\
\hline$<10$ Years & 5 & 45 \\
\hline 10-19 Years & 2 & 18 \\
\hline $20+$ Years & 4 & 36 \\
\hline \multicolumn{3}{|l|}{ Practice Setting } \\
\hline Academic & 10 & 90 \\
\hline Private & 1 & 9. \\
\hline \multicolumn{3}{|l|}{ EMR $^{\mathrm{a}}$ active } \\
\hline Yes & 8 & 72 \\
\hline No & 3 & 27 \\
\hline \multicolumn{3}{|l|}{ No active EMR } \\
\hline EMR pending within 1 Year & 2 & 66 \\
\hline NO pending EMR & 1 & 33 \\
\hline \multicolumn{3}{|l|}{ Care Plan Preference } \\
\hline Electronic & 9 & 81 \\
\hline Hard Copy & 2 & 18 \\
\hline
\end{tabular}

Available Support Staff

\begin{tabular}{|c|c|c|}
\hline \multicolumn{3}{|c|}{ Nurse Practitioner $(n=10)$} \\
\hline None & 4 & 40 \\
\hline 1 & 5 & 50 \\
\hline$>1$ & 1 & 10 \\
\hline \multicolumn{3}{|c|}{ Physician's Assistant $(n=10)$} \\
\hline None & 4 & 40 \\
\hline 1 & 5 & 50 \\
\hline$>1$ & 1 & 10 \\
\hline \multicolumn{3}{|c|}{ Nurse - other $(n=10)$} \\
\hline 1 & 9 & 90 \\
\hline$>1$ & 1 & 10 \\
\hline \multicolumn{3}{|c|}{ Medical Assistant $(n=10)$} \\
\hline None & 1 & 10 \\
\hline 1 & 7 & 70 \\
\hline$>1$ & 2 & 20 \\
\hline \multicolumn{3}{|c|}{ Resident $(n=9)$} \\
\hline None & 5 & 55.5 \\
\hline 1 & 4 & 44.4 \\
\hline \multicolumn{3}{|c|}{ Fellow $(n=7)$} \\
\hline None & 6 & 85.7 \\
\hline 1 & 1 & 14.3 \\
\hline Student ( & & \\
\hline
\end{tabular}

Table 2 Site Characteristics (Continued)

\begin{tabular}{lll}
\hline & $\mathrm{n}$ & $\%$ \\
\hline None & 6 & 85.7 \\
1 & 1 & 14.3 \\
$\quad$ Volunteer $(n=8)$ & 7 & 87.5 \\
$\quad$ None & 1 & 12.5 \\
1 & & \\
Social Worker & 6 & 75.0 \\
$\quad$ None & 2 & 25.0 \\
1 & & $\mathrm{n} / \mathrm{a}$ \\
Clinical Resources (Mean \pm SD) & $3 \pm 1$ & $\mathrm{n} / \mathrm{a}$ \\
Number of clinic rooms & $2.37 \pm 1.10$ & $\mathrm{n} / \mathrm{a}$ \\
General outpatient room & $1.18 \pm 0.75$ & $\mathrm{n} / \mathrm{a}$ \\
$\quad$ Treatment / procedure room & $1.0 \pm 0.87$ & \\
Consultation & &
\end{tabular}

one consultation room in which to see patients. Rather than slow room turnover, providers opted to complete the $\mathrm{BC}-\mathrm{SCP}$ away from patients, in their own personal time, to avoid interruption to clinic flow. Although a nurse was available within most practice environments, support staff were not plentiful as evidenced by $\geq 40 \%$ of practices without an APP, $>55 \%$ without a specialty resident, and $>85 \%$ without a clinical fellow. Ultimately, given the increased time for SCP completion, without a clear increase in billing, the SCP completion by genitourinary specialists does not seem sustainable.

Multiple studies in other cancer populations have cited lack of staff, SCP templates, time to complete SCP, training and reimbursement, and the time necessary to obtain information required to create an SCP, as barriers for SCP use [39]. Our results suggest that the majority of the BC-SCPs in this study were completed by the patients' providers devoting a mean of $12.3 \mathrm{~min}$ to this task. As health systems in the US continue to mobilize efforts to comply with the $\mathrm{CoC}$ recommendations to provide treatment summary and SCPs to eligible patients [39-41], it will be incumbent upon Cancer Center leaders to provide appropriate support staff to achieve this goal within working time periods. As the emphasis on clinical productivity and patient throughput grows across academic and private health-centers, providers could potentially be constrained by time, which might limit the use of the BC-SCP by providers during consultations as well as sharing and discussing the BC-SCP with patients during the clinical encounter. This necessitates the expansion of work force (e.g., the involvement of trained clinical support personnel) or provision of extra billable time to ensure optimal use of the BC-SCP in clinical settings. Moreover a successful survivorship program requires adoption of a multidisciplinary 
Table 3 Care plan completion

\begin{tabular}{|c|c|}
\hline Variable & n (\%) \\
\hline Number of Patients & 54 \\
\hline \multicolumn{2}{|l|}{ Patient Gender $(n=47)$} \\
\hline Male & $35(74.5)$ \\
\hline Female & $12(25.5)$ \\
\hline \multicolumn{2}{|l|}{ Patient Race $(n=52)$} \\
\hline White & $49(94.2)$ \\
\hline Black & $2(3.8)$ \\
\hline Asian & 0 \\
\hline Other - Hispanic & $1(1.9)$ \\
\hline \multicolumn{2}{|l|}{ Patient Insurance Type $(n=51)$} \\
\hline Medicare & $23(45.1)$ \\
\hline Medicaid & 0 \\
\hline Private & $19(37.3)$ \\
\hline VA & - \\
\hline None & $1(2)$ \\
\hline Other & $8(15.7)$ \\
\hline \multicolumn{2}{|l|}{ Cancer Stage $(n=51)$} \\
\hline TO & $4(7.5)$ \\
\hline $\mathrm{T} 1$ & $9(16.7)$ \\
\hline $\mathrm{T} 2$ & $19(35.2)$ \\
\hline $\mathrm{T} 2 \mathrm{~N} 2$ & $1(1.9)$ \\
\hline T3 & $4(7.5)$ \\
\hline T4 & $2(3.7)$ \\
\hline Ta & $6(11.1)$ \\
\hline Tis & $3(5.6)$ \\
\hline Tx & $3(5.6)$ \\
\hline \multicolumn{2}{|c|}{ Provider Type Completing Care Plan $(n=18)$} \\
\hline Urologist & $14(77.7)$ \\
\hline Medical Oncologist & $1(5.6)$ \\
\hline $\begin{array}{l}\text { Advanced Practice Providers (Nurse } \\
\text { Practitioner / Physician's Assistant) }\end{array}$ & $2(11.1)$ \\
\hline Resident / Fellow & $1(5.6)$ \\
\hline \multicolumn{2}{|c|}{ Completed Care Plan by Provider type $(n=54)$} \\
\hline Urologist & $41(75.9)$ \\
\hline Medical Oncologist & $5(9.3)$ \\
\hline Medical Assistant & - \\
\hline Social Worker & - \\
\hline $\begin{array}{l}\text { Advanced Practice Providers (Nurse } \\
\text { Practitioner / Physician's Assistant) }\end{array}$ & $7(13)$ \\
\hline Resident / Fellow & $1(1.9)$ \\
\hline Student / Volunteer & - \\
\hline Mean Completion Time: Mean (range) & $12.2 \min (2-25)$ \\
\hline \multicolumn{2}{|l|}{$\begin{array}{l}\text { Completed in the presence of the } \\
\text { patient? }(n=50)\end{array}$} \\
\hline Yes & $1(2)$ \\
\hline
\end{tabular}

Table 3 Care plan completion (Continued)

\begin{tabular}{ll}
\hline Variable & $\mathrm{n}(\%)$ \\
\hline No & $49(98)$ \\
Gere was care plan completed? $(n=49)$ & $1(2)$ \\
Staff room & $15(30.6)$ \\
Procedure / Treatment room & $12(24.5)$ \\
Consultation room & $16(32.7)$ \\
Outside of clinic & $5(10.2)$ \\
Did completion result in a higher billing code: $(n=46)$ & \\
Yes & 0 \\
No & $46(100)$ \\
Mean Number of & \\
New patients & 4 \\
Other patients & 16 \\
\hline
\end{tabular}

approach; a dedicated survivorship program, possibly run by an APP and mental health providers trained in $\mathrm{BC}$ care and surveillance with consultation by a physician provider could accommodate and make valuable the use of a SCP. However, the provision of resources and funding remain a major challenge to establish the necessary infrastructure required for such a dedicated approach.

Survivorship care planning may be an important driver of surveillance and follow-up for cancer survivors; however, over a decade into the proposed SCP by IOM, robust evidence supporting the large-scale implementation of care plans amongst cancer survivors or to abandon SCPs altogether is lacking [42]. Although SCPs have largely been tested in colorectal, breast, ovarian and childhood cancers, they haven't gained much momentum in the urologic community despite the existence of guidelines on surveillance of urologic cancers treated at various stages. This was part of the incentive to consider the current study. We believe that incorporating a disease-specific SCP, developed via an iterative process with input from patients at multiple points, into active practice settings would truly provide a holistic approach to patient care. However, observed challenges in the actual use of SCP remain to be addressed.

In sum, BC-SCPs are necessary to improve patient care and outcomes. Survivors treated for NMIBC need regular cystoscopic surveillance to detect recurrence. MIBC survivors treated with radical cystectomy or radical radiotherapy need frequent monitoring to detect metastatic disease as well as follow-up for changes in urinary, bowel, metabolic, sexual disturbances, and psychological and emotional consequences. Gilbert et al. suggested that care of urologic cancer survivors may be improved by i) the widespread implementation and 
Table 4 Care plan completion time stratified by Clinico-pathologic parameters

\begin{tabular}{|c|c|c|c|c|}
\hline Variable & Completed in $\leq 10 \min (\mathrm{N}=18) \mathrm{N}(\%)$ & Completed in > $10 \min (N=23) \mathrm{N}(\%)$ & Chi-square & $p$-Value \\
\hline \multicolumn{5}{|l|}{ Patient Age } \\
\hline$\leq 65$ Years & $2(14.3 \%)$ & $8(42.1 \%)$ & 2.83 & .959 \\
\hline$>65$ Years & $12(85.7 \%)$ & $11(57.9 \%)$ & & \\
\hline \multicolumn{5}{|l|}{ Patient Gender } \\
\hline Male & $12(75 \%)$ & $12(66.7 \%)$ & 2.38 & .595 \\
\hline Female & $4(25 \%)$ & $6(33.3 \%)$ & & \\
\hline \multicolumn{5}{|l|}{ Race } \\
\hline White & $17(94.4 \%)$ & $20(90.9 \%)$ & 1.78 & .673 \\
\hline Other & $1(5.6 \%)$ & $2(9.1 \%)$ & & \\
\hline \multicolumn{5}{|l|}{ Insurance Type } \\
\hline Medicare & $9(52.9 \%)$ & $10(47.6 \%)$ & 1.06 & .744 \\
\hline Other & $8(47.1 \%)$ & $11(52.4 \%)$ & & \\
\hline \multicolumn{5}{|l|}{ Disease Stage2 } \\
\hline NMIBC & $4(23.5 \%)$ & $8(36.4 \%)$ & 2.94 & .086 \\
\hline MIBC & $19(76.5 \%)$ & $14(63.6 \%)$ & & \\
\hline \multicolumn{5}{|l|}{ Clinic Visits } \\
\hline$\leq 4$ visits & $8(47.0 \%)$ & $15(71.4 \%)$ & 1.99 & .656 \\
\hline$\geq 5$ visits & $9(53.0 \%)$ & $6(28.6 \%)$ & & \\
\hline \multicolumn{5}{|l|}{ Provider Type } \\
\hline Urologist & $13(72.2 \%)$ & $17(73.9 \%)$ & 2.968 & .397 \\
\hline Medical Oncologist & $3(16.7 \%)$ & $2(8.7 \%)$ & & \\
\hline Other & $2(11.1 \%)$ & $4(17.4 \%)$ & & \\
\hline \multicolumn{5}{|l|}{ Years in Practice } \\
\hline$\leq 10$ Years & $3(33.3 \%)$ & $6(60 \%)$ & .533 & .766 \\
\hline 11-19 Years & $3(33.3 \%)$ & $2(20 \%)$ & & \\
\hline$\geq 20$ Years & 3 (33.3\%) & $2(20 \%)$ & & \\
\hline
\end{tabular}

Table 5 Evaluation of the Feasibility of the BC-SCP in Clinical Settings

\begin{tabular}{|c|c|c|}
\hline Encounter Questions & $\begin{array}{l}\text { Number of Encounter } \\
\text { Responses }\end{array}$ & $\begin{array}{l}\text { Median (mean) response; } \\
\text { scale range: } 1 \text { (Not at all) - } 7 \text { (Very much) }\end{array}$ \\
\hline Was the information that was requested clear? & 48 & $6(5.65)$ \\
\hline Was it difficult to locate the requested information? & 51 & $2(3.10)$ \\
\hline $\begin{array}{l}\text { Is this format (assuming further revision) one you would consider using in your } \\
\text { practice? }\end{array}$ & 50 & $4(4.04)$ \\
\hline Did the care plan completion hamper clinic flow? If yes, please comment above. & 34 & $3.5(4.07)$ \\
\hline $\begin{array}{l}\text { Do you currently have ample clinic resources to complete survivorship care plans } \\
\text { in all new patients? }\end{array}$ & 50 & $4(3.3)$ \\
\hline $\begin{array}{l}\text { Was the patient an engaged and active participant in the completion of the care } \\
\text { plan? }\end{array}$ & 35 & $2(3)^{a}$ \\
\hline Did the care plan completion enhance the dialogue between you and the patient? & 35 & $2(2.89)^{\mathrm{a}}$ \\
\hline $\begin{array}{l}\text { Did the patient appear interested in receiving the appendix portion of the care } \\
\text { plan? }\end{array}$ & 33 & $3(3.36)^{a}$ \\
\hline
\end{tabular}


application of SCPs, ii) adoption of evidence-based surveillance practices in the follow-up of cancer survivors, and iii) the development of disease-specific and institution-based survivorship clinics to systematically improve survivorship care [42]. Moreover, Gilbert suggested that the use of a standardized SCP can facilitate communication between providers, serve as a guide for follow-up care, and help coordinate disease and health surveillance [43].

Our study has limitations. First, the survey population is limited to a very small number of providers, albeit from various institutions across the country with a total of 54 patients information included. Because of the small survey sample size, we did not examine potential interactions between site and provider characteristics on the SCP evaluation or completion time. Second, a majority of the providers in our study were urologists with a small proportion of the providers being medical oncologists and NPs. Another limitation of our study is the absence of the views of PCPs regarding the content and usefulness of the BC-SCP. The primary focus of our project at this point, however, was to assess the acceptability and feasibility of implementing the BC-SCP in clinical practice of the specialty providers involved directly in cancer care. The usefulness of the actual content and its validity would need to be assessed in future studies. Finally, just over half of the BC-SCPs were completed in the consultation room and procedure/treatment room, while the remainder were completed elsewhere. It might be interesting to see if there would be any difference to the quality of information and timing for completion if the SCPs were to be completed during the actual patient-physician encounter, to obtain views of primary care physicians on the ease of use of SCPs in primary care settings to improve follow-up care, and to incorporate SCPs into EMR; future studies could potentially evaluate this. Larger randomized controlled studies on innovative models of SCP, the impact of these SCPs on oncological, psychosocial and resource outcomes are required. Despite these limitations however, our findings have implications for utilizing and implementation of the BC-SCP that we have developed.

As the use of SCPs increases, it is important to enhance research comparing the effectiveness, usefulness, impactful elements of SCP and the timing in which they should be delivered [44]. Further studies assessing a range of outcomes in various survivor populations and using different outcome measures are required [45] to fully understand the efficacy of SCPs.

\section{Conclusion}

A BC specific SCP has clinical relevance but there are significant challenges for providers' use of the SCP with $\mathrm{BC}$ patients in an active practice setting in specialty clinics.. Urologic specialists can complete BC-SCPs in a timely manner but will likely choose to do this outside of the patient encounter which may limit the impact of the SCP on patients. Increased clinic resources and personnel may be leveraged to complete $\mathrm{BC}$-SCPs on a greater scale in an effort to comply with $\mathrm{CoC}$ guidelines but to also enhance patient experience. Integration of the BC-SCP within the EMR may increase the efficiency of BC-SCP implementation and the likelihood of integrating it into regular communications with a range of healthcare providers.

\section{Supplementary information}

Supplementary information accompanies this paper at https://doi.org/10 1186/s12913-020-05533-7.

Additional file 1. The Bladder Cancer Survivorship Care Plan (BC-SCP). This file includes information pertaining to general information, background information, treatment plan and summary, follow-up care.

Additional file 2. Resource Guide. This file incorporates preventive / health maintenance information, alarm symptoms and signs to watch out for, potential late-effects of cancer, benefit resources, resources for health care providers, resources for bladder cancer survivors and families.

Additional file 3. Encounter Data Sheet. This file includes information pertaining to the logistics of completing the BC-SCP such as the provider type and the time taken to complete the BC-SCP, 8 item-survey with 7point Likert response scale.

\section{Abbreviation}

APP: Advanced Practice Providers; BC: Bladder Cancer; BC-SCP: Bladder Cancer Survivorship Care Plan; BCAN: Bladder Cancer Advocacy Network; CoC: Commission on Cancer; EMR: Electronic Medical Record; FG: Focus Group; IOM: Institute of Medicine; MIBC: Muscle Invasive Bladder Cancer; NCCN : National Comprehensive Cancer Network; NMIBC: Non Muscle Invasive Bladder Cancer; NP: Nurse Practitioner; PA: Physician Assistant; QoL: Quality of Life; SCP: Survivorship Care Plans; SD: Standard Deviation; SWG: Survivorship Working Group

\section{Acknowledgements}

The authors would like to acknowledge Bladder Cancer Advocacy Network (BCAN) for their support.

\section{Authors' contributions}

All authors have reviewed and approved the manuscript for submission. CTL: Principal investigator of the study. Contributed to the design of the study, drafted the SCP, led the focus groups, acquisition of study data, edited the manuscript, approved the final version of the manuscript. NEM: Involved in data analyses, manuscript writing and revision, and approved the submitted submitted manuscript. SP: Involved in drafting the manuscript, manuscript revisions and submission, and approved the submitted manuscript. QNS: Involved in data analyses, manuscript preparation, and approved the submitted manuscript. PKA: Involved in data collection and approved the submitted manuscript. TMD: Involved in data collection and approved the submitted manuscript. MD: Involved in data collection and approved the submitted manuscript. SMG: Involved in data collection and approved the submitted manuscript. HHG: Involved in data collection and approved the submitted manuscript. SJH: Involved in data collection and approved the submitted manuscript. MH: Involved in data collection and approved the submitted manuscript. JHC: Involved in data collection and approved the submitted manuscript. MOD: Involved in data collection and approved the submitted manuscript. MK: Involved in data collection and approved the submitted manuscript. LIK: Involved in data collection and approved the submitted manuscript. WK: Involved in data collection and approved the submitted manuscript. DZQ: Involved in data collection and approved the submitted manuscript. AS: Involved in data collection and approved the 
submitted manuscript. GDS: Involved in data collection and approved the submitted manuscript. DML: Study Co-PI, involved in design of the work, drafted the work, approved the submitted manuscript. Additionally, all authors have agreed to be personally accountable to their own contributions and ensure that questions related to the accuracy or integrity of any part of the work, even ones in which the author was not personally involved, are appropriately investigated, resolved, and the resolution documented in the literature.

\section{Funding}

This study was funded by Bladder Cancer Advocacy Network (BCAN). BCAN is a national advocacy organization committed to supporting patients and families affected by bladder cancer as well as advancing research in the field. Funds were used to assist with data collection, data analyses, and support a research coordinator.

\section{Availability of data and materials}

The datasets generated and/or analyzed during the current study are not publicly available due to most of our data being qualitative information and analysis involving FGs; but are available from the corresponding author on reasonable request. Data regarding participating sites, data analysis, the SCP designed and used, resource guide and encounter data sheet are all included as supplementary files in this submission.

\section{Ethics approval and consent to participate}

All procedures performed in studies involving human participants were in accordance with the ethical standards of the institutional and/or national research committee and with the 1964 Helsinki declaration and its later amendments or comparable ethical standards. The study was approved by the Institutional Review Board (IRB) of the University of Michigan (the lead institution) and the participating institutions (Study HUM00056082). Informed verbal consent was obtained from all individual participants included in the study.

\section{Consent for publication}

Not applicable.

\section{Competing interests}

Authors SP, QNS, PKA, TMD, MD, SMG, HHG, MH, MOD, MK, WK, DZQ, AS,

GDS, DML declare that they have no conflicts of interest.

CTL received a research grant from MelRite and is a consultant with Merck. She has no conflicts related to the content of this manuscript.

NEM received research grants from The National Institute of Health and The American Cancer Society. She received an honorarium for participating in the Incyte Bladder Cancer Advisory Board.

$\mathrm{SH}$ received a research grant from National Cancer Institute.

$\mathrm{JHC}$ received research funding from Genetech/Roche and is a consultant with Astra-Zeneca, Genetech/Roche, Foundation Medicine. She has no conflicts related to the content of this manuscript.

LIK received research funding from Astellas, Allergan, AstraZeneca, Augmenix, Bayer, BioXcel, CU Optics, CUSP Lancelot, Dendreon, Exact Sciences, Ferring, FKD, Genetech/Roche, GenomeDx, Genomic Health, Janssen, Merck, Myovant, Nucleix, Pfizer, Pharmtech/Neru, Precision Biopsy, Precision Med, Siemens, Spectrum, Urogen, Vaxiion. He is a Consultant / Advisory for 3D Biopsy, Abbvie, Astellas, Astra-Zeneca, Augmenix, Bayer, Dendreon, Ferring, Janssen, Pfizer, Precision Biopsy, Spectrum, Vaxiion. He is a speaker for Amgen, Astellas, Bayer, Janssen, Pfizer and is the owner of Swan Valley Medical. He has no conflicts related to the content of this manuscript.

\section{Author details}

${ }^{1}$ Department of Urology, The Ohio State University, Columbus, OH, USA. ${ }^{2}$ Department of Urology and Oncological Sciences, Icahn School of Medicine at Mount Sinai, 1 Gustave L Levy Place, New York, NY 10029, USA. ${ }^{3}$ University of Nevada Reno School of Medicine, Reno, NV, USA. ${ }^{4}$ National Cancer Institute, Bethesda, MD, USA. ${ }^{5}$ University of Wisconsin, Madison, WI, USA. ${ }^{6}$ Moffitt Cancer Center, Tampa, FL, USA. ${ }^{7}$ Social Work Program, University of Houston-Downtown, Houston, TX, USA. ${ }^{8}$ Section of Infectious Diseases, Baylor College of Medicine, Houston, TX, USA. ${ }^{9}$ Smith Institute for Urology, Hofstra School of Medicine/Northwell Health System, Lake Success, NY, USA.

${ }^{10}$ Sidney Kimmel Cancer Center at John Hopkins, Baltimore, MD, USA.

${ }^{11}$ University of lowa, lowa City, IA, USA. ${ }^{12}$ Penn State Health, Hershey, PA,
USA. ${ }^{13}$ The Urology Center of Colorado, Denver, CO, USA. ${ }^{14}$ McGill University Health Center, Montreal, Canada. ${ }^{15}$ Bladder Cancer Advocacy Network, Bethesda, MD, USA. ${ }^{16}$ University of Texas, Southwestern, Dallas, TX, USA. ${ }^{17} \mathrm{NYU}$ Langone Health, New York, NY, USA. ${ }^{18}$ Baylor College of Medicine, Houston, TX, USA

Received: 28 October 2019 Accepted: 13 July 2020

Published online: 24 July 2020

\section{References}

1. Malats N, Real FX. Epidemiology of bladder cancer. Hematol Oncol Clin. 2015;29:177-89.

2. Mohamed NE, Pisipati $\mathrm{S}$, Lee $\mathrm{CT}$, et al. Unmet informational and supportive care needs of patients following cystectomy for bladder cancer based on age, sex, and treatment choices. Urol Oncol. 2016; p. 531. e7-531. e14.

3. Chung J, Kulkarni GS, Morash R, et al. Assessment of quality of life, information, and supportive care needs in patients with muscle and nonmuscle invasive bladder cancer across the illness trajectory. Support Care Cancer. 2019;27:1-9.

4. Mohamed NE, Herrera PC, Hudson S, et al. Muscle invasive bladder cancer: examining survivor burden and unmet needs. J Urol. 2014;191:48-53.

5. Lee CT, Mei M, Ashley J, et al. Patient resources available to bladder cancer patients: a pilot study of healthcare providers. Urology. 2012;79:172-7.

6. Grunfeld E, Fitzpatrick R, Mant D, et al. Comparison of breast cancer patient satisfaction with follow-up in primary care versus specialist care: results from a randomized controlled trial. Br J Gen Pract. 1999:49:705-10.

7. Grunfeld E, Levine MN, Julian JA, et al. Randomized trial of long-term follow-up for early-stage breast cancer: a comparison of family physician versus specialist care. J Clin Oncol. 2006;24:848-55.

8. Khatcheressian JLW, Antonio C, Smith TJG, Eva MHBV, Victor G, et al. American Society of Clinical Oncology 2006 update of the breast cancer follow-up and management guidelines in the adjuvant setting. J Clin Oncol. 2006;24:5091-7.

9. Runowicz $C D$, Leach $C R$, Henry NL, et al. American cancer society/American society of clinical oncology breast cancer survivorship care guideline. CA Cancer J Clin. 2016;66:43-73.

10. Dawes AJ, Hemmelgarn M, Nguyen DK, et al. Are primary care providers prepared to care for survivors of breast cancer in the safety net? Cancer. 2015;121:1249-56

11. Neuman HB, Jacobs EA, Steffens NM, et al. Oncologists' perceived barriers to an expanded role for primary care in breast cancer survivorship care. Cancer Med. 2016;5:2198-204.

12. Dulko D, Pace CM, Dittus KL, et al. Barriers and facilitators to implementing cancer survivorship care plans. In: Oncology nursing forum: NIH Public Access; 2013. p. 575

13. Institute of Medicine and National Research Council. From Cancer Patient to Cancer Survivor: Lost in Transition. Washington, DC: The National Academies Press. 2006. https://doi.org/10.17226/11468.

14. Chen RC, Hoffman KE, Sher DJ, et al. Development of a standard survivorship care plan template for radiation oncologists. Pract Radiat Oncol. 2016;6:57-65.

15. Key Components of Survivorship Care. Available from: https://www.asco. org/practice-guidelines/cancer-care-initiatives/prevention-survivorship/ survivorship/survivorship. Accessed 8 Oct 2017.

16. Ahmadi $\mathrm{H}$, Jewett MA, Shore ND, et al. The need for survivorship care in genitourinary cancers: considerations from SUO and LUGPA. Urol Pract. 2016:3:62-9.

17. Oeffinger KC, Hudson MM, Mertens AC, et al. Increasing rates of breast cancer and cardiac surveillance among high-risk survivors of childhood Hodgkin lymphoma following a mailed, one-page survivorship care plan. Pediatr Blood Cancer. 2011;56:818-24.

18. Blaauwbroek R, Barf H, Groenier K, et al. Family doctor-driven follow-up for adult childhood cancer survivors supported by a web-based survivor care plan. J Cancer Surviv. 2012;6:163-71.

19. Spain PD, Oeffinger KC, Candela J, et al. Response to a treatment summary and care plan among adult survivors of pediatric and young adult cancer. J Oncol Pract. 2012;8:196-202.

20. Grunfeld E, Mant D, Yudkin P, et al. Routine follow up of breast cancer in primary care: randomised trial. BMJ. 1996;313:665-9.

21. Grunfeld E, Julian JA, Pond G, et al. Evaluating survivorship care plans: results of a randomized, clinical trial of patients with breast cancer. J Clin Oncol. 2011;29:4755-62. 
22. Blinder VS, Norris WW, Peacock NW, et al. Patient perspectives on breast cancer treatment plan and summary documents in community oncology care. Cancer. 2013;119:164-72.

23. Hershman DL, Greenlee H, Awad D, et al. Randomized controlled trial of a clinic-based survivorship intervention following adjuvant therapy in breast cancer survivors. Breast Cancer Res Treat. 2013;138:795-806.

24. Brothers BM, Easley A, Salani R, et al. Do survivorship care plans impact patients' evaluations of care? A randomized evaluation with gynecologic oncology patients. Gynecol Oncol. 2013;129:554-8.

25. Jefford M, Lotfi-Jam K, Baravelli C, et al. Development and pilot testing of a nurse-led posttreatment support package for bowel cancer survivors. Cancer Nurs. 2011;34:E1-E10.

26. Mayer DK, Gerstel A, Walton AL, et al. Implementing survivorship care plans for colon cancer survivors. Oncol Nurs Forum. 2014;41(3):266-73.

27. Brennan M, Gormally J, Butow P, et al. Survivorship care plans in cancer: a systematic review of care plan outcomes. Br J Cancer. 2014;111:1899.

28. Moretto P, Jewett MA, Basiuk J, et al. Kidney cancer survivorship survey of urologists and survivors: the gap in perceptions of care, but agreement on needs. Can Urol Assoc J. 2014;8:190.

29. Napoles AM, Santoyo Olsson J, Chacon L, Stewart AL, et al. Feasibility of a mobile phone app and telephone coaching survivorship care plan among Spanish speaking breast cancer survivors. JMIR Cancer. 2019;5(2):e13543.

30. Chrischilles EA, McDowell BD, Rubenstein $L$, et al. Survivorship care planning and its influence on long-term patient-reported outcomes among colorectal and lung cancer survivors: the CanCORS disease-free survivor follow-up study. J Cancer Surviv. 2015;9(2):269-78. https://doi.org/10.1007/s11764-014-0406-y.

31. Kapoor A, Nambisan P. Personal decision support for survivor engagement: formulation and feasibility evaluation of a conceptual framework for implementing online cancer survivorship care plans. BMC Med Inform Decis Mak. 2020;20(1):59.

32. Mohamed NE, Lee CT. Quality of life and survivorship. In: Bladder cancer. West Sussex: Wiley; 2015. p. 384-94.

33. Mohamed N, Diefenbach M, Goltz H, et al. Muscle invasive bladder cancer: from diagnosis to survivorship. Adv Urol. 2012;2012:142135.

34. Svatek RS, Rosenberg JE, Galsky MD, et al. Summary of the 6th annual bladder cancer think tank: New directions in urologic research. Urol Oncol. 2013; p. 968-73.

35. Miles MB, Huberman AM. Qualitative data analysis: a sourcebook. Beverly Hills: Sage Publications; 1994

36. Averill JB. Matrix analysis as a complementary analytic strategy in qualitative inquiry. Qual Health Res. 2002;12(6):855-66.

37. Muhr T. ATLAS.ti - A Prototype for the Support of Text Interpretation. In: Tesch R, editor. Qualitative Sociology, vol. 14. New York: Human Science Press; 1991. p. S.349-71.

38. Tabachnick B, Fidell L. Multivariate analysis of variance and covariance. Using Multivariate Stat. 2007:3:402-7.

39. Birken SA, Mayer DK, Weiner BJ. Survivorship care plans: prevalence and barriers to use. J Cancer Educ. 2013;28:290-6.

40. CoC. Continuum of Care Services: Survivorship Care Plan. In: Surg AC, editor. Cancer Program Standards: Ensuring Patient-Centered Care: Chicago, American College of Surgeons; 2015. p. 58-9.

41. CoC (Commission on Cancer). 2019. A quality program of the American College of Surgeons. https://www.facs.org/ /media/files/quality\%2 Oprograms/cancer/coc/draft_coc_revised_standards_may2019.ashx. Accessed 5 May 2020.

42. van de Poll-Franse LV, Nicolaije KA, Ezendam NP. The impact of cancer survivorship care plans on patient and health care provider outcomes: a current perspective. Acta Oncol. 2017;56:134-8.

43. Gillbert SM, Miller DC, Hollenbeck BK, et al. Cancer survivorship: challenges and changing paradigms. J Urol. 2008;179:431-8.

44. Shay LA, Schmidt S, Dioun SI, Grimes A, Embry L. Receipt of a survivorship care plan and self-reported health behaviors among cancer survivors. J Cancer Surviv. 2019;13(2):180-6.

45. Brennan ME, Gormally JF, Butow P, Boyle FM, Spillane AJ. Survivorship care plans in cancer: a systematic review of care plan outcomes. $\mathrm{Br} J$ Cancer. 2014;111(10):1899-908

\section{Publisher's Note}

Springer Nature remains neutral with regard to jurisdictional claims in published maps and institutional affiliations.

Ready to submit your research? Choose BMC and benefit from:

- fast, convenient online submission

- thorough peer review by experienced researchers in your field

- rapid publication on acceptance

- support for research data, including large and complex data types

- gold Open Access which fosters wider collaboration and increased citations

- maximum visibility for your research: over $100 \mathrm{M}$ website views per year

At BMC, research is always in progress.

Learn more biomedcentral.com/submissions 